\title{
Response of a Gibberellin-deficient Potato Mutant to Induction and Growth Regulators as a Working Model for Tuber Initiation
}

\author{
Bing Wang ${ }^{1}$ \\ Jackson Laboratory, Bar Harbor, ME 04609
}

\author{
Alan R. Langille ${ }^{2,3}$ \\ Horticulture Program, Department of Plant, Soil, and Environmental \\ Sciences, University of Maine, Orono, ME 04469
}

Additional index words. gibberellic acid, gibberellin inhibitor, Solanum andigena, Solanum tuberosum

\begin{abstract}
To explore further the role endogenous gibberellins play in the formation of the potato tuber, a gibberellin-deficient dwarf of Solanum tuberosum subsp. andigena (PI 281036) and its normal sibling were used in this study. Because gibberellins are known to be elevated and to affect tuber formation negatively when potato plants are grown under long day conditions, test plants were first grown in a growth chamber under conditions that did not favor tuberization (noninducing conditions). The stem apices of dwarfs received weekly applications of a $100-\mathrm{ppm}$ gibberellic acid $\left(\mathrm{GA}_{3}\right)$ solution to achieve growth similar to that of normal plants. When the requisite height was achieved, five dwarfs and five normal sibs were treated to foliar runoff with a $100-p p m ~ G A_{3}$ solution, and a like number of these plants received a control spray of distilled water. These plants were then placed in a growth chamber adjusted to inducing conditions for tuber initiation. An additional five dwarfs and five normal sibs were sprayed with $600 \mathrm{ppm}$ paclobutrazol (PB), a gibberellin inhibitor, and a similar number of plants received a distilled water control spray. This group of plants was returned to the noninducing chamber. After 1 week, plants were removed from their respective growth chambers and divided into two-node apical, medial, and basal leaf-bud cuttings. Basal buds of the cuttings were buried in moist potting mix in a mist chamber with a 16-hour photoperiod. Rhizome and tuberization responses were evaluated after 3 weeks. The experiment was repeated and results combined for statistical treatment. Orthogonal contrasts revealed that apical cuttings from normal donor plants produced rhizomes only under noninducing conditions or when treated with $\mathrm{GA}_{3}$. No rhizomes formed on apical cuttings from normal plants growing under inducing conditions (favoring tuberization) or noninduced plants receiving PB (a gibberellin inhibitor). For apical dwarf tissues, there were no effects of treatments on rhizome production, except for the PB treatment, which resulted in shorter rhizomes. Tuberization was observed in apical tissues of induced and noninduced dwarfs, which lack the ability to synthesize gibberellin, but only in induced cuttings of normal sibs. Noninduced dwarf cuttings tuberized as well as those from normal plants receiving the antigibberellin treatment. Tuber weights from induced apical cuttings of dwarfs and normal sibs were not significantly different. These results support the significant role played by gibberellins in tuber formation.
\end{abstract}

Normal tuber formation in the potato (Solanum tuberosum L.) involves two closely related yet distinctly different processes:

\footnotetext{
Received for publication 6 July 2006. Accepted for publication 9 Nov. 2006.

The research, as part of the Masters of Science dissertation of the senior author, was supported by the Maine Agricultural and Forest Expt. Sta. under provisions of the Hatch Act.

Maine Agricultural and Forest Experiment Station Publication no. 2912.

We thank Prof. W.A. Halteman, Department of Mathematics, for advice on statistical treatment of data. ${ }^{1}$ Former graduate student.

${ }^{2}$ Professor.

${ }^{3}$ To whom reprint requests should be addressed; e-mail alan.langille@umit.maine.edu
}

development of the rhizome at an underground node, followed by tuber formation at the subapical region of the rhizome (Booth, 1963). These processes in Solanum species, especially $S$. tuberosum subsp. andigena Hawkes, are controlled by environmental factors, primarily temperature and photoperiod, that regulate levels of endogenous growth substances. Rhizome growth is favored by long days (Chapman, 1958) and, when coupled with high temperatures, "noninducing conditions" are created that result in poor tuber development (Gregory, 1956; Slater, 1968). Noninducing conditions also result in elevated gibberellin levels in potato plants (Okazawa, 1959, 1960). Conversely, Gregory (1956) also noted that short days and low night temperatures ("inducing condi- tions") promote tuberization, and Dostal (1945) and Madec (1963) provided evidence for a specific tuber-forming stimulus formed in leaves under inducing conditions.

Gibberellins have also been implicated in the tuberization process (Kumar and Wareing, 1972). For example, Okazawa $(1959,1960)$ observed that endogenous gibberellin content was highest in potato plants grown under noninducing conditions and decreased when plants were moved to those favoring tuberization. Hammes and Nel (1975) proposed that tuber formation is controlled by a balance between endogenous gibberellins and the tuber-forming stimulus. For tuberization to occur, gibberellin levels must decrease below some minimum value.

Bamberg and Hanneman (1991) reported identifying a gibberellin-deficient potato dwarf in their breeding progeny, characterized by dark-green rosette foliage with short internodes. Its dwarfism could be reversed by foliar gibberellin treatment. van den Berg et al. (1995) subsequently determined that this type of dwarfism was related to the plant's inability to convert Gibberellin $\mathrm{A}_{12}$ to Gibberellin $\mathrm{A}_{35}$, thus preventing formation of a physiologically active form.

In an attempt to resolve the nagging question of whether tubers form in response to increased "tuberizing hormone" levels under inducing conditions or are the result of a decrease in endogenous gibberellins, the following study was conducted. The effects of inductive conditions and certain growth regulators on the tuberization response of leaf-bud cuttings of a gibberellin-deficient potato dwarf and its normal sibling were evaluated as a means of assessing the role gibberellins play in controlling tuber formation.

\section{Materials and Methods}

True seeds of a dwarf clone of $S$. tuberosum subsp. andigena (PI 281036) and its normal sibling were obtained from the InterRegional Potato Introduction Sta., Sturgeon Bay, Wisc. Before initiating this study, these plants had been grown in growth chambers and produced tubers. Tubers from the respective clones were then exposed to room temperature to break dormancy. When sprouts reached 1 to $2 \mathrm{~cm}$ in length, tubers were carefully planted in 7.6-cm-diameter pots filled with ProMix (Premier Horticulture, Red Hill, Pa.). Pots were then placed in an incubator adjusted to $28{ }^{\circ} \mathrm{C}$ day $/ 25^{\circ} \mathrm{C}$ night temperature with an 18 -h photoperiod providing a photosynthetic photon flux of $36 \mu \mathrm{mol} \cdot \mathrm{m}^{-2} \cdot \mathrm{s}^{-1}$. Apical meristems of dwarfs were treated weekly with a small volume of $100 \mathrm{ppm}$ gibberellic acid $\left(\mathrm{GA}_{3}\right)$ solution to encourage internode elongation. When stems of both dwarfs and normal sibs had elongated to provide at least eight nodes, stem segments with one to two nodes were excised and cultured on MS medium (Murashige and Skoog, 1962). Subculturing provided sufficient numbers of dwarfs and normal siblings for the study. 
In each experiment, 24 uniform dwarfs and 24 normal sibs were repotted into $15-\mathrm{cm}$ standard pots filled with ProMix and placed in a growth chamber adjusted to noninducing conditions $\left(28{ }^{\circ} \mathrm{C}\right.$ day and $25{ }^{\circ} \mathrm{C}$ night temperature with a 18 -h photoperiod). Plants were watered and fertilized with $100 \mathrm{~mL}$ 15:30:15 soluble fertilizer $\left(2.5 \mathrm{~g} \cdot \mathrm{L}^{-1}\right)$. A single drop of $100 \mathrm{ppm} \mathrm{GA}_{3}$ solution was applied by micropipet to the stem apex of the dwarfs twice per week to stimulate stem elongation. Twenty of the most uniform dwarfs and 20 normal sibs were selected for further experimentation. The remaining plants were sampled weekly to ascertain timing of rhizome development.

At an early stage of rhizome elongation and 1 week after the $\mathrm{GA}_{3}$ treatment to dwarfs had ended, plants had reached $\approx 45 \mathrm{~cm}$ in height. Then five dwarfs and five normal sibs were randomly selected and sprayed to foliar runoff with a $100 \mathrm{ppm} \mathrm{GA}_{3}$ solution containing Tween $80\left(1 \mathrm{~mL} \cdot \mathrm{L}^{-1}\right)$. Another five dwarfs and five normal sibs were similarly treated with distilled water and Tween 80 as controls. Leaves of both groups were allowed to air dry before being placed in an inducing chamber adjusted to $21{ }^{\circ} \mathrm{C}$ day and $11{ }^{\circ} \mathrm{C}$ night temperature with a $10-\mathrm{h}$ photoperiod. The remaining 10 dwarfs and 10 normal sibs were maintained under noninducing conditions. Of these, five dwarfs and five normal sibs received a foliar spray of $600 \mathrm{mg} \cdot \mathrm{L}^{-1}$ paclobutrazol (PB) solution containing Tween $80\left(1 \mathrm{~mL} \cdot \mathrm{L}^{-1}\right)$ to foliar runoff. The remaining five dwarfs and five normal sibs were sprayed with distilled water with Tween 80 as a control and were also allowed to air dry before returning to the noninducing growth chamber. Appropriate concentrations for $\mathrm{GA}_{3}$ and $\mathrm{PB}$ solutions were determined in previous tests (data not shown).

Six days after foliar treatment, plants were removed from the chambers and the central axis of each was divided into apical, medial, and basal leaf-bud cuttings each with two nodes, according to Ewing and Wareing (1978). Cuttings were placed in moist potting mix in a mist chamber with supplemental lighting providing a $16-\mathrm{h}$ photoperiod with an illumination of $65 \mu \mathrm{mol} \cdot \mathrm{s}^{-1} \cdot \mathrm{m}^{-2}$. Care was taken to ensure that the basal bud, with the leaf removed, was covered with potting mix while the upper leaf was exposed. Three weeks after leaf-bud cuttings were placed in the mist chamber, buds on individual cuttings were examined for rhizomes and tubers. Rhizome lengths and tuber weights were determined. This study was repeated and the results were combined.

This experiment was originally designed as a $4 \times 2 \times 3$ factorial with four growth conditions (inducing conditions, inducing conditions with $\mathrm{GA}_{3}$, noninducing conditions, and noninducing conditions with $\mathrm{PB}$ ) $\times$ two plant types (normal and dwarf) $\times$ three stem locations (apical, medial, and basal). However, because there were several treatment combinations that resulted in neither rhizomes nor tubers, the 17 nonzero treatment combinations were analyzed as a oneway design using Duncan's multiple range test as a follow-up to identify individual treatment differences.

\section{Results}

Because gibberellins act as antagonists to tuberization, rhizome length as an indicator of tissue gibberellin content could provide useful information on the role these hormones play in tuber formation. With this in mind, the effects of growing conditions and chemical treatment, plant type, and tissue location on rhizome length are presented in Table 1. No rhizomes formed on apical control cuttings from normal induced plants nor did they form on apical cuttings from noninduced normal donor plants treated with PB. In both cases, gibberellin production was curtailed either because of the "adverse environmental conditions" experienced by induced plants or by the inhibitory action of $\mathrm{PB}$ on gibberellin synthesis under conditions that would ordinarily favor their production. Application of $\mathrm{GA}_{3}$ to normal donor plants grown under inducing conditions produced apical cuttings with rhizomes that were significantly longer than those on the noninduced apical control cuttings. Because dwarf plants lacked the requisite gibberellin synthetic system, rhizomes produced on apical sections of these tissues did not differ in length regardless of the treatment imposed. No obvious pattern for rhizome development based upon stem location emerged from these data.

Data presented for tuber production as influenced by the three-factor interaction of growth conditions, plant type, and stem location, concentrated only on the apical cuttings, the proposed sites of gibberellin production, and their response record (Table 2). For normal sib apical cuttings, induced tissues produced tubers whereas noninduced tissues did not. For dwarf apical cuttings, however, both induced and noninduced treatments resulted in tubers. Tubers produced on the induced apical dwarf cuttings did not differ in weight from those on normal induced tissues. The $\mathrm{GA}_{3}$ treatment resulted in no tuber formation on induced apical tissues of either source.

Weight of tubers produced on noninduced control dwarf apical cuttings did not differ from those on dwarf tissues that had received the PB treatment. Interestingly, weight of these tubers did not differ from those on normal tissue receiving $\mathrm{PB}$, indicating the inhibitory effect of endogenous gibberellins had been negated in each case. Additionally, the weight of tubers formed on induced apical

Table 1. Effect of plant type, induction, growth regulator treatments, and tissue location on mean rhizome length on two-node potato leaf-bud cuttings.

\begin{tabular}{|c|c|c|c|c|c|}
\hline \multirow[b]{3}{*}{ Plant type } & \multirow[b]{3}{*}{ Location } & \multicolumn{4}{|c|}{ Rhizome length $(\mathrm{cm})^{\mathrm{z}}$} \\
\hline & & \multicolumn{2}{|c|}{ Induced } & \multicolumn{2}{|c|}{ Noninduced } \\
\hline & & Control & $\mathrm{GA}_{3}$ & Control & PB \\
\hline \multirow[t]{3}{*}{ Normal sib } & Apical & 0.00 & $11.61 \mathrm{a}$ & $4.89 \mathrm{bc}$ & 0.00 \\
\hline & Medial & 3.10 cdefg $^{y}$ & 3.10 cdefg & $3.65 \mathrm{cdef}$ & 0.00 \\
\hline & Basal & 4.10 bcde & $3.48 \mathrm{cdef}$ & $4.70 \mathrm{bcd}$ & 0.00 \\
\hline \multirow[t]{3}{*}{ Dwarf } & Apical & $1.95 \mathrm{fg}$ & 2.94 defg & $2.12 \mathrm{ef}$ & $1.35 \mathrm{~g}$ \\
\hline & Medial & $4.70 \mathrm{bcd}$ & 3.00 cdefg & 0.00 & 0.00 \\
\hline & Basal & 3.03 cdefg & $5.71 \mathrm{~b}$ & $2.30 \mathrm{efg}$ & 0.00 \\
\hline
\end{tabular}

${ }^{\mathrm{z}}$ Means are the average of those rhizomes present in each treatment. (Those with no rhizomes were not included in the calculation.) Means followed by a different letter were significantly different by Duncan's multiple range test $(P<0.05)$.

${ }^{y}$ Duncan's multiple range test in this table was only conducted for 17 treatments, and each of them contains no less than one replicate having rhizomes. Zeros in the other seven treatments indicate that these treatments had no observations and thus were not subjected to Duncan's multiple range test.

Observations were made after 3 weeks.

$\mathrm{GA}_{3}$, gibberellic acid; $\mathrm{PB}$, paclobutrazol.

Table 2. Effect of plant type, induction, growth regulator treatments, and tissue location on mean tuber fresh weight on two-node potato leaf-bud cuttings.

\begin{tabular}{|c|c|c|c|c|c|}
\hline \multirow[b]{3}{*}{ Plant type } & \multirow[b]{3}{*}{ Location } & \multicolumn{4}{|c|}{ Tuber fresh weight $(\mathrm{g})^{\mathrm{z}}$} \\
\hline & & \multicolumn{2}{|c|}{ Induced } & \multicolumn{2}{|c|}{ Noninduced } \\
\hline & & Control & $\mathrm{GA}_{3}$ & Control & $\mathrm{PB}$ \\
\hline \multirow[t]{3}{*}{ Normal sib } & Apical & $0.79 \mathrm{ab}^{\mathrm{y}}$ & 0.00 & 0.00 & $0.28 \mathrm{def}$ \\
\hline & Medial & $1.06 \mathrm{a}$ & 0.00 & $0.57 \mathrm{bcd}$ & $0.74 \mathrm{~b}$ \\
\hline & Basal & 0.50 bcde & 0.00 & 0.00 & $0.29 \mathrm{def}$ \\
\hline \multirow[t]{3}{*}{ Dwarf } & Apical & $0.77 \mathrm{ab}$ & 0.00 & $0.18 \mathrm{ef}$ & 0.18 ef \\
\hline & Medial & 0.37 cdef & $0.26 \mathrm{def}$ & $0.62 \mathrm{bc}$ & 0.22 ef \\
\hline & Basal & 0.34 cdef & 0.00 & $0.13 \mathrm{f}$ & $0.06 \mathrm{f}$ \\
\hline
\end{tabular}

${ }^{z}$ Means are the average of those tubers present in each treatment. (Those with no tubers were not included in calculation.) Means followed by a different letter were significantly different by Duncan's multiple range test $(P<0.05)$.

${ }^{y}$ Duncan's multiple range test in this table was only conducted for 17 treatments, and each of them contains no less than one replicate having tubers. Zeros in the other seven treatments indicate that these treatments had no observations and thus were not subjected to Duncan's multiple range test.

Observations were made after 3 weeks.

$\mathrm{GA}_{3}$, gibberellic acid; PB, paclobutrazol. 
cuttings of dwarfs and normal sibs were not significantly different.

When the effect of plant location from which cuttings were taken was evaluated, the following pattern emerged: For normal tissues, the medial cuttings tended to produce larger tubers, regardless of the environmental conditions. The exception was the induced control treatment in which, although larger, the medial tuber was not significantly larger than the apical tuber. No tubers were produced on any of the $\mathrm{GA}_{3}$-treated normal tissues. A similar pattern was observed for the dwarf explants, except for the induced control treatment in which the apical cutting produced the heavier tuber. Although the heaviest tuber was noted on the medial segment of the PB-treated tissues, it did not differ significantly from the other locations.

\section{Discussion}

Gibberellins are known to act as antagonists to tuberization (Kumar and Wareing, 1972; Railton and Wareing, 1973), and Okazawa $(1959,1960)$ has reported that gibberellin levels were highest in potato plants grown under environmental conditions that did not favor tuber set. Furthermore, Chapman (1958) noted that potato rhizomes were longer and more plentiful when plants were grown under these same noninductive, long day conditions. Thus, the negative effect of inducing conditions on rhizome length noted in Table 1 was expected, and was found, but only in the apical segments of normal plants, where Jones and Phillips (1966) noted gibberellins were synthesized. The PB treatment concentration was sufficient to inhibit gibberellin production in the noninduced tissues, and no stem location exhibited rhizome elongation. The $\mathrm{GA}_{3}$ treatment was also sufficient to overcome the effect of induction to stimulate rhizome growth in normal apical explants, whereas noninduced normal apical segments with intact gibberellin synthetic systems produced somewhat shorter rhizomes. Dwarf apical tissues, without the ability to synthesize gibberellins, all produced rhizomes, possibly as a result of the presence of residual $\mathrm{GA}_{3}$ from earlier treatments applied to achieve proper growth.

Gregory (1956) had observed that no tubers formed on apical cuttings taken from noninduced plants and those that were subsequently maintained under noninducing conditions. But in the current study, noninducing conditions, known to favor elevated gibberellin production, resulted in tubers produced on the gibberellin-deficient dwarf tissues. Normal sib tissue, with its capacity to produce gibberellins intact, was incapable of forming tubers under these noninducing conditions. The fact that tubers that formed on induced apical cuttings of normal and dwarf tissues were the same weight is noteworthy (Table 2). This observation would suggest that it was the amount of "tuberizing hormone" produced under inducing conditions that determined the degree of tuberization observed, rather than the presence or absence of gibberellins. This conclusion could be drawn because inducing conditions were associated with zero rhizome production for normal apical segments with an intact gibberellin synthetic system whereas minimal rhizome growth was recorded for the gibberellin-deficient dwarf tissues (Table 1).

The observation that significant rhizome elongation was observed for the noninduced treatment that produced no tubers on apical normal tissues gives credence to the theory advanced by Hammes and $\mathrm{Nel}$ (1975) that gibberellin levels must decrease below some minimum value before tubers may form. This is further supported by the fact that when $\mathrm{PB}$ was applied to the normal noninduced donor plants, gibberellin production was inhibited, thus eliminating rhizome elongation but permitting tubers to form on apical tissues. Further evidence for this theory comes from the observation in Table 2 that tuber size in dwarf apical control segments that lacked gibberellin synthetic capability was significantly influenced by induction. That is, without the negative influence of endogenous gibberellin on tuber growth, it is tempting to speculate that more "tuberizing hormone" accumulated under inducing rather than noninducing conditions to produce a heavier tuber. Malkawi (1999) observed that normal tuber formation under inducing conditions in 'Katahdin' plants was associated with significant increases in levels of both cis-zeatin riboside and jasmonic acid, both of which have been identified as possible tuberizing agents (Mauk and Langille, 1978; Koda et al., 1991).

As had been previously noted by Gregory (1956) and Langille and Hepler (1992), prior exposure of donor plants to inducing conditions resulted in improved tuber formation on cuttings when compared with noninduced control tissues (Table 2). However, even though both types of donor plants were grown under inducing conditions, the presence of endogenous gibberellins produced in the apex of the induced normal tissue had an inhibitory influence on developing tubers, resulting in their size being similar to those of the dwarf (Table 2). Studies by Lovell and Booth (1967) and Tizio (1971) have demonstrated the adverse effect foliar $\mathrm{GA}_{3}$ application had on tuber formation. A similar negative effect on tuber weight was observed for the $\mathrm{GA}_{3}$ treatment when applied to induced plants with only medial cuttings of induced dwarf tissues producing tubers (Table 2). This could suggest that because gibberellins were lacking in these tissues, an insufficient quantity of $\mathrm{GA}_{3}$ had translocated to the medial region to prevent tuberization. The PB treatment produced the expected effect of inhibiting gibberellin synthesis (van den Berg et al., 1995) and permitting tuber formation on normal tissues grown under noninducing conditions, whereas no tubers formed on the control apical segments that would be expected to have intact gibberellin synthetic systems. What is noteworthy is that apical tuber weights of the noninduced dwarf control and PB treatments did not differ. Because there was no gibberellin synthetic pathway in the dwarf tissues to inhibit, the PB treatment did not influence tuber growth (Table 2).

If gibberellins are synthesized in the immature leaves of the stem apex as proposed by Jones and Phillips (1966), the largest tubers might be expected to form on the axillary buds the farthest away from this gibberellin source. When tuber weights for control tissues were examined, this was not found to be the case, because both apical and medial tubers were larger than those formed on basal cuttings, although not always significantly so (Table 2). This observation contradicts findings from an earlier study conducted in this laboratory (Langille and Hepler, 1992) in which percent tuberization of noninduced 'Katahdin' nodal segments increased with distance from the GA source.

Results of the current study aid in clarifying the role played by endogenous gibberellins in the formation of the tuber. The current study corroborates the theory advanced by Hammes and $\mathrm{Nel}$ (1975) that tuber formation in the potato is controlled by a balance between the inhibitory action of endogenous gibberellins and some "tuberizing factor." As they suggested, the gibberellins must decrease below some minimum level in order for the tuberization process to proceed.

\section{Literature Cited}

Bamberg, J.B. and R.E. Hanneman, Jr. 1991. Characterization of a new gibberellin relate dwarfing locus in potato (Solanum tuberosum L.). Amer. Potato J. 68:45-52.

Booth, A. 1963. The role of growth substances in the development of stolons, p. 99-113. In: J.D. Ivins and F.L. Milthorpe (eds.). The growth of the potato. Butterworths, London.

Chapman, H.W. 1958. Tuberization in the potato plant. Physiol. Plant. 11:215-224.

Dostal, R. 1945. On the question of organogens in plants. Bull. Intl. Acad. Tech. Cl. Sci. Math. Nat. Med. 46:1-20.

Ewing, E.E. and P.F. Wareing. 1978. Shoot, stolon, and tuber formation on potato (Solanum tuberosum L.) cuttings in response to photoperiods. Plant Physiol. 61:348-353.

Gregory, L.E. 1956. Some factors for tuberization in the potato plant. Amer. J. Bot. 43:281-288.

Hammes, P.S. and P.C. Nel. 1975. Control mechanisms in the tuberization process. Potato Res. $18: 262-272$

Jones, R.L. and I.D.J. Phillips. 1966. Organs of gibberellin synthesis in light-grown sunflower plants. Plant Physiol. 41:1381-1386.

Koda, Y., Y. Kikuta, H. Tazaki, Y. Tsujino, S. Sakamura, and T. Yoshihara. 1991. Potato tuber-inducing activities of jasmonic acid and related compounds. Phytochemistry 30:14351438 .

Kumar, D. and P.F. Wareing. 1972. Factors controlling stolon development in the potato plant. New Phytol. 71:639-648.

Langille, A.R. and P.R. Hepler. 1992. Effect of three anti-gibberellin growth retardants on tuberization of induced and non-induced 'Katahdin' potato leaf-bud cuttings. Am. Potato J. 69:131-141.

Lovell, P. and A. Booth. 1967. Effect of gibberellic acid on growth, tuber formation, and carbohydrate 
distribution in Solanum tuberosum. New Phytol. 66:525-537.

Madec, P. 1963. Tuber-forming substances in the potato, p. 121-131. In: J.D. Ivins and F.C. Milthorpe (eds.). The growth of the potato. Butterworths, London.

Malkawi, A.M. 1999. Natural products from Solanum tuberosum L. University of Maine, Orono, Maine, PhD Diss.

Mauk, C.S. and A.R. Langille. 1978. Physiology of tuberization in Solanum tuberosum L. ciszeatin riboside in the potato plant: Its identification and changes in endogenous levels as influenced by temperature and photoperiod. Plant Physiol. 62:438-442.
Murishige, T. and F. Skoog. 1962. A revised medium for the rapid growth and bioassays with tobacco tissue cultures. Physiol. Plant. 15:473-496.

Okazawa, Y. 1959. Studies on the occurrence of natural gibberellin and its effects on the tuber formation of potato plants. Proc. Crop. Sci. Soc. Jpn. 28:129-133.

Okazawa, Y. 1960. Studies on the relation between the tuber formation of potato and its natural gibberellin content. Proc. Crop. Sci. Soc. Jpn. 29:121-124.

Railton, I.D. and P.F. Wareing. 1973. Effects of daylength on endogenous gibberellins in leaves of Solanum andigena I: Changes in levels of free acidic gibberellin-like substances. Physiol. Plant. 28:88-94.

Slater, J.W. 1968. The effect of night temperature on the initiation of the potato. Eur. Potato J. 11:14-32.

Tizio, R. 1971. Action et role probable de certaines gibberellins (A1, A3, A4, A5, A7, A9, et A13) sur la croissance des stolons et la tuberisation de la pomme de terre (Solanum tuberosum L.). Potato Res. 14:193-204.

van den Berg, J.H., I. Simko, P.J. Davies, E.E. Ewing, and A. Halinska. 1995. Morphology and $\left({ }^{14} \mathrm{C}\right)$ gibberellin $\mathrm{A}_{12}$ metabolism in wildtype and dwarf Solanum tuberosum ssp. andigena grown under long and short photoperiods. J. Plant Physiol. 146:467-473. 